\title{
O TRABALHO REMOTO NA ADMINISTRAÇÃO PÚBLICA BRASILEIRA: desafios e perspectivas
}

\author{
REMOTE WORK IN BRAZILIAN PUBLIC ADMINISTRATION: challenges and \\ perspectives
}

\author{
André do Carmo Lucas ${ }^{1}$ \\ Rayane Leite dos Santos ${ }^{2}$
}

RESUMO: O objetivo deste estudo foi analisar a adoção do teletrabalho no serviço público brasileiro, discutindo as suas regulamentações, vantagens e desvantagens, desafios e perspectivas. Essa modalidade de trabalho vem sendo adotado em vários países há décadas, entretanto, surgiu timidamente no Brasil, ganhando destaque somente nos últimos anos. Com a adoção do trabalho remoto, o Estado visa aumentar a eficiência na prestação dos serviços públicos, focando na entrega de resultados e reduzindo custos administrativos. Todavia o teletrabalho ainda apresenta desafios importantes a serem superados pelos órgãos públicos e servidores como problemas de adaptação, de comunicação, sensação de isolamento, além de problemas para a gestão de pessoas no que diz respeito à supervisão no teletrabalho. Essa pesquisa mostrou que, apesar dos notáveis avanços, ainda existem muitos desafios a serem superados para que essa forma de trabalho possa alcançar plenamente seu potencial. Porém, observou-se que os ganhos são muito superiores, tanto para o servidor, quanto órgão e sociedade.

Palavras-chave: Teletrabalho. Home office. Tecnologia. Serviço público.

ABSTRACT: The objective of this study was to analyze the adoption of telework in the Brazilian public service, discussing its regulations, advantages and disadvantages, challenges and perspectives. This type of work has been adopted in several countries for decades, however, this modality appeared timidly in Brazil, gaining prominence only in recent years. With the adoption of remote work, the State aims to increase efficiency in the provision of public services, focusing on delivering results and reducing administrative costs. However, teleworking presents important challenges to be overcome by public agencies and civil servants, such as problems of adaptation, communication, feeling of isolation, as well as problems for the management of people with regard to supervision in teleworking. This research showed that, despite the notable advances, there are still challenges to overcome so that this form of work can reach its full potential. However, it

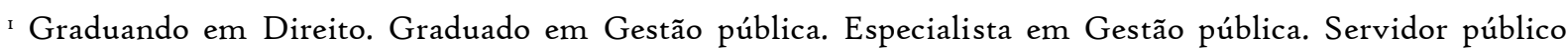
atuando como Tecnólogo em Gestão Pública/gestão financeira no Instituto Federal do Maranhão - IFMA. Email: rayannyleite@hotmail.com.

${ }^{2}$ Graduada em Tecnologia de Alimentos. Mestre em Ciência Animal. Doutoranda em Ciência e Tecnologia de Alimentos na Universidade Federal do Ceará - UFC. 
was observed that the gains are much higher, both for the civil servant, as well as the institution and society.

Keywords: Teleworking. Home Office. Technology. Public service.

\section{INTRODUÇÃO}

As constantes mudanças provocadas pelo avanço da tecnologia da informação, bem como o conturbado cenário político e econômico e epidemiológico vivenciado atualmente no Brasil, mostra a necessidade de as organizações públicas repensarem suas estruturas e regimes de trabalho, de forma a se adequarem às novas demandas apresentadas pela sociedade. Importante frisar também que a administração pública do país vem se tornando alvo de inflamadas discussões quanto a dimensão, legitimidade, viabilidade e produtividade do Estado.

Com cada vez mais apelo no atual mercado de trabalho, a adoção do trabalho remoto é uma tendência em muitas empresas do setor privado. E o serviço público também tem buscado se adequar a essas novas tendências. Aos poucos, o trabalho remoto - também chamado de teletrabalho ou home office - é adotado no setor público. E essa modalidade veio com o objetivo de impulsionar e, ao mesmo tempo, criar ferramentas para o servidor realizar suas atribuições de maneira mais aprazível, criativa, inovadora, com o condão de modernização do serviço público (ROCHA; AMADOR, 2018).

No Brasil, a adoção desse regime de trabalho no setor público ainda era incipiente até o surgimento da pandemia do Novo Coronavírus em 2020. Algumas organizações públicas já adotavam ou estudavam a possibilidade de adotar a modalidade de home office e as experiências, em geral, parecem indicar que essas iniciativas são exitosas, pois, muitos casos mostraram um aumento expressivo da produtividade e redução de custos.

O trabalho remoto no setor público pode ser conceituado como aquele em que o servidor pode desenvolver parte ou todo o seu trabalho fora das dependências da instituição, apoiado na utilização das novas ferramentas tecnológicas, em especial, o computador, acesso à internet, hardwares e softwares necessários para a realização de suas atribuições (SOBRATT, 20r6). Apresentando-se, portanto, como uma alternativa ao trabalho presencial. Por isso, nesse momento de recomendação de distanciamento social, uma das medidas tomadas pelo governo para evitar o aumento da disseminação do Novo Coronavírus foi permitir que servidores públicos executem suas atividades à distância, no modelo de teletrabalho.

Mas há ainda muitas controvérsias sobre este tema, pois não está consolidado em quais casos específicos é possível a conversão da jornada tradicional de trabalho para o referido regime no setor público. Resta o questionamento de como tem se adotado efetivamente o home office no serviço público. E principalmente a preocupação em manter uma boa política de fiscalização, confidencialidade, alto desempenho e estratégias para evitar prejuízos ao atendimento do interesse público.

Frente a esse contexto, é notório reconhecer que o tema merece relevância científica e há uma necessidade de aprofundamento desse modelo trabalhista, analisando os impactos na gestão pública, bem como a sua influência nos aspectos da cultura organizacional da administração pública. Por isso, objetivo deste estudo foi analisar a adoção do teletrabalho no serviço público brasileiro, discutindo as suas regulamentações, vantagens e desvantagens, desafios e as perspectivas de inserção do servidor público nesse regime de trabalho. 


\section{Legislação do trabalho remoto}

O trabalho remoto vem sendo adotado em vários países há décadas, entretanto, no Brasil, esta modalidade de trabalho surgiu timidamente, ganhando destaque somente nos últimos anos, especificamente com o surgimento da Lei $\mathrm{n}^{\mathrm{O}}$ 12.551/2011, que alterou o art. 6은 da Consolidação das Leis do Trabalho (CLT) equiparando os efeitos jurídicos da subordinação exercida por meios telemáticos e informatizados à exercida por meios pessoais e diretos (MENDES; OLIVEIRA; VEIGA, 2020). O art. 6을 da CLT passou a viger com a seguinte redação:

Art. 6ㅇ. Não se distingue entre o trabalho realizado no estabelecimento do empregador, o executado no domicílio do empregado e o realizado a distância, desde que estejam caracterizados os pressupostos da relação de emprego.

Parágrafo único. Os meios telemáticos e informatizados de comando, controle e supervisão se equiparam, para fins de subordinação jurídica, aos meios pessoais e diretos de comando, controle e supervisão do trabalho alheio (BRASIL, 20II).

E mais recentemente, a Lei $\mathrm{n}$ 13.467 entrou em vigor, a partir da reforma trabalhista de 2017. Essa norma regulamenta o trabalho remoto em empresas privadas no Brasil. Ela convenciona o vínculo trabalhista por meio de contrato individual, que estabelece as tarefas a serem desenvolvidas e a responsabilidade pela aquisição, conservação ou fornecimento das ferramentas de tecnologia da informação e mobiliário adequado ao trabalho remoto. $\mathrm{E}$ também, define formas de reembolso das despesas feitas pelo empregado. Trata também do termo de responsabilidade do trabalhador em relação às questões de segurança e saúde do trabalhador, em que o funcionário se compromete em seguir todas as indicações disponibilizadas pelo empregador de modo a evitar doenças e acidentes de trabalho (REIS, 2018).

$\mathrm{Na}$ esfera da administração pública, por sua vez, ainda não existia uma lei geral que regulamentasse o teletrabalho. O projeto de lei no $2723 /$ I5 que autorizaria entidades públicas federais a adotarem o sistema de trabalho remoto nas atividades em que os resultados pudessem ser mensurados estava em tramitação na Câmara dos Deputados para aprovação, todavia, foi arquivado (BRASIL, 2015). Por causa disso as regulamentações vinham sendo efetivadas por um número pequeno de órgãos quando comparadas à iniciativa privada, por meio de normas próprias, como portarias, resoluções ou atos de gestão, conforme estrutura, características e peculiaridades de cada instituição.

Visando uma melhor regulamentação dessa modalidade, em 2018, o atualmente extinto Ministério do Planejamento, Desenvolvimento e Gestão- MPDG publicou a Instrução Normativa (IN) $n$ o $_{1}$, estabelecendo orientações para a implantação do Programa de Gestão pelos órgãos públicos integrantes do Sistema de Pessoal Civil da Administração Federal- SIPEC (BRASIL, 20I8). Esta instrução normativa criou métodos e exigências gerais para o controle da frequência dos servidores que participavam do programa, através da implementação do home office de maneira facultativa à Administração Pública, ocorrendo em conformidade com a conveniência e interesse do serviço público e embasada em critérios técnicos.

Em julho de 2020, o governo federal definiu novas regras para o teletrabalho por meio da IN n ${ }^{\circ} 65$ que revoga IN n ${ }^{\circ}$ I e incentiva a execução do trabalho na modalidade remota, estabelecendo orientações para a adoção do regime de teletrabalho nos órgãos e entidades integrantes do SIPEC (BRASIL, 2020). Com a promulgação dessa nova IN o governo visa modernizar a gestão de pessoas e aumentar a eficiência na prestação dos serviços públicos.

Foram considerados positivos os resultados alcançados com o teletrabalho "forçado" pela pandemia, por isso o objetivo da IN $n^{\circ} 65$ é simplificar as regras do programa de gestão 
e expandir a adoção do teletrabalho, focando na entrega de resultados e reduzindo custos administrativos.

A adoção do programa de gestão fica a critério dos órgãos e entidades da Administração Pública Federal e deve ser implantada em função da conveniência e do interesse do serviço (BRASIL, 2020). $\mathrm{O}$ artigo $2^{\circ}$ da referida IN estabelece quem pode participar do teletrabalho:

I - servidores públicos ocupantes de cargo efetivo;

II - servidores públicos ocupantes de cargo em comissão, declarado em lei de livre nomeação e exoneração;

III - empregados públicos regidos pelo Decreto-Lei no 5.452 , de I을 de maio de 1943, em exercício na unidade; $\mathrm{e}$

IV - contratados temporários regidos pela Lei no 8.745 , de 9 de dezembro de 1993 (BRASIL, 2020).

Essa normativa determina também que o os servidores que aderirem ao teletrabalho deverão assinar e cumprir o plano de trabalho. Sendo que o monitoramento de cada entrega cabe ao chefe imediato, e este pode desligar o servidor do teletrabalho em caso de descumprimento ao estabelecido no plano. Além disso, o servidor precisa permanecer disponível para contatos telefônicos, checar regularmente sua caixa de e-mail, apresentar-se na instituição sempre que convocado e zelar pelas informações acessadas de forma remota, observando as normas internas e externas de segurança da informação (BRASIL, 2020).

\section{I Requisitos para implantação do teletrabalho no setor público}

Alguns dos requisitos para a implantação do teletrabalho, conforme a IN no 6o/2020, são de que sejam atividades mensuráveis, além da obrigatoriedade de avaliação da produtividade e dos resultados das unidades que optarem por adotar o programa (BRASIL, 2020).

A possibilidade de adotar o trabalho remoto depende de diversas variáveis. Inicialmente, o servidor necessita demonstrar interesse em trabalhar remotamente e seu supervisor deve admitir sua participação, avaliando se o servidor possui o perfil adequado ao home office e se as tarefas desenvolvidas podem ser realizadas nesse regime. Inclusive, pode ocorrer controle de jornada de trabalho, sendo necessário que o funcionário esteja disponível para acessar o sistema sempre que for solicitado. É comum ter prioridade aqueles que exercem atividades com maior exigência de concentração e que não necessitam de interação com os demais colegas. Também há preferência para pessoas com deficiência ou que tenham familiar com deficiência, gestantes e lactantes ou aquelas com limitações para o deslocamento (ROCHA; AMADOR, 2018).

Dessarte, ficou estabelecido pela IN 65 (BRASIL, 2020) que o teletrabalho não poderá ser adotada em atividades cuja natureza exija a presença física do servidor na instituição ou que sejam desenvolvidas por meio de trabalho externo e não pode diminuir a capacidade de atendimento de setores que atendam ao público interno e externo (BRASIL, 2020).

Por sua vez, a Sociedade Brasileira de Teletrabalho e Televendas - SOBRATT (2020) recomenda, em sua cartilha de orientações para implantação e prática do teletrabalho, que ao implantar a modalidade trabalho remoto, primeiramente seja feito um projeto piloto, com um número reduzido de participantes voluntários, mas que seja uma amostra representativa da instituição. E deve-se necessariamente considerar também as questões referentes a Tecnologia e Segurança das Informações, jurídico-trabalhistas e macroprocessos (estratégico). 
Para O'Neill et al. (2009) os fatores pessoais que influenciam no sucesso dos teletrabalhadores são: a capacidade de distinguir a vida pessoal da profissional, a habilidade de trabalhar sem supervisão constante e o potencial de superar a ameaça de isolamento.

Deste modo, a instituição que decidir adotar o teletrabalho precisará determinar regras claras e estabelecer quais são as funções/cargos que poderão usufruir deste regime. Conhecer o perfil de cada servidor também é imprescindível para definir quem vai se adequar ao tipo de trabalho, além disso, os gestores precisam ainda promover encontros e reuniões periódicos para realizar avaliações e determinar novas rotinas e metas.

\section{O trabalho remoto na administração pública brasileira}

Apesar de não existir diferenças consideráveis entre o home office no setor público e privado, estudiosos da gestão pública acreditam que o progresso do trabalho remoto no serviço público tende a sofrer mais oposição por parte da sociedade pela sua própria essência e por isso, necessita ser pautado pela transparência. Desse modo, o órgão público que resolver adotar essa modalidade de trabalho precisa estar pronto para prestar satisfações à sociedade.

Para Leite e Muller (2017) a probabilidade de implementação do teletrabalho na esfera pública, pode ser definida com base em políticas públicas que buscam a modernização do aparato estatal e expansão do governo eletrônico.

Embora incipiente, a implantação do home office na administração pública vem ganhando muito espaço nesse setor. $O$ primeiro caso relatado de adoção legal dessa modalidade de trabalho foi no Serviço Federal de Processamento de Dados - SERPRO, iniciando sua experiência em 2006. Por sua natureza predominante de trabalho de programação e processamento de dados, o SERPRO já tinha um contexto muito favorável para o teletrabalho: atuação individual independente, com entregas individuais e possibilidade de comunicação à distância. $\mathrm{O}$ ingresso dos funcionários nesse regime era feito através da análise de perfil junto ao gestor da área, auxiliado pelo setor de Gestão de Pessoas e, como empresa celetista, fornecia os equipamentos necessários para o empregado trabalhar em casa (OLIVEIRA; PANTOJA, 2018).

Segundo informações acessadas na página virtual da empresa, esse programa apresentou um ganho em produtividade de 10,5\% e uma economia em logística de 47,1\% (SILVA, 2015).

Além do SERPRO, diversas instituições públicas já adotam esse sistema, tem-se como exemplo o Tribunal de Contas da União, a Advocacia Geral da União e a Receita Federal. Ainda, a Procuradoria Geral da República, as Agências Reguladoras e vários Tribunais Federais e Estaduais também já abraçam o modelo de teletrabalho (ROCHA; AMADOR, 2018).

E nesses últimos meses de 2020 e 2021, com a pandemia do coronavírus quase todos os setores públicos tiveram que adotar, pelo menos parcialmente, essa forma de trabalho. Neste cenário, para os órgãos que já adotavam essa modalidade, tem sido mais fácil lidar com essas novas circunstâncias, enquanto que para muitos que não adotavam vêm enfrentando muitos desafios. Assim, percebe-se a importância de se buscar novas metodologias de trabalho para estar melhor preparado para lidar com eventuais adversidades como pandemias e catástrofes por exemplo.

De todo modo, a decisão para a adoção do home office no setor público deve primar por resultados satisfatórios que atendam ao interesse da sociedade (SILVA, 2015). Assim sendo, as atividades preconizadas devem ter como orientação as atribuições em que seja possível verificar o desempenho do servidor e a qualidade do serviço realizado (OLIVEIRA; 
PANTOJA, 2018). Portanto, determinados setores da Administração Pública que necessitam fazer atendimento ao público ou carecem de interação funcional para seu andamento, não podem adotar deliberadamente o teletrabalho porque o interesse público não pode ser suprimido.

Goulart (2009) propõe um novo modelo de teletrabalho que se baseia na análise das variáveis consideradas essenciais para essa modalidade. Nessa proposta, observar as ferramentas tecnológicas disponíveis, os papéis existentes, a legislação vigente e as características individuais de cada trabalhador consistem numa etapa fundamental para viabilizar a adoção desse modelo de trabalho.

É importante ressaltar que nem todo servidor público está apto a ser inserido no teletrabalho, assim, este regime é vedado ao profissional que se encontrar em estágio probatório ou aos que tenham sofrido penalidades disciplinares. Pois, nessa modalidade, exige-se que o servidor possua uma boa reputação e seja muito responsável, de modo que as tarefas sejam realizadas com responsabilidade e segurança (BOHLER, 2019).

Deste modo, esse tipo de trabalho requer aptidões especiais dos teletrabalhadores e dos órgãos, sendo preciso articular o método de comunicação a partir dos meios de informação disponíveis, uma vez que o funcionário precisa de equipamentos adequados para realização das suas tarefas (SILVA, 2015).

O fato é que o trabalho remoto é uma boa alternativa para diminuição dos custos operacionais e no crescimento da eficiência e dos índices de produtividade, reduzindo os custos com a estrutura física das unidades operacionais. Além disso, também contribui para a melhoria de indicadores socioambientais através da diminuição na emissão dos poluentes emitidos pelos meios de transporte, bem como a queda do consumo de papel e de outros bens e serviços nesses espaços (MENDES; OLIVEIRA; VEIGA, 2020).

Ademais, mesmo fazendo parte da realidade da administração pública brasileira, Silva (2015) mostra que aparenta existir resistência das instituições públicas e dos servidores em relação a essa forma de trabalho. Segundo a autora, é importante que o Estado procure evoluir na adoção do home office nesse setor, visto que essa modalidade pode trazer inúmeras vantagens, tanto ao servidor como para o órgão que o adota. Contudo, sem desconsiderar os entraves e desafios implicados nesse regime de trabalho.

\section{3.r Desvantagens e desafios do trabalho remoto}

Pesquisas realizadas na administração pública e analisadas nesse estudo, revelam que o teletrabalho apresenta desafios importantes a serem superados pelos órgãos públicos. Desafios estes, que consistem em evitar a falta de adaptação, de comunicação, diferenças na relação entre trabalhador presencial e teletrabalhador, além de problemas com infraestrutura tecnológica.

Segundo Bohler (2019), em sua pesquisa sobre teletrabalho no setor público, os servidores entrevistados apontaram como principais pontos negativos do teletrabalho a diminuição da convivência social e os custos com equipamentos, internet e luz, além do aumento da produtividade cobrado a esses profissionais. De acordo com alguns entrevistados, essa imposição de acréscimo de produtividade é inconveniente uma vez que essa forma de atividade gera economia para o órgão. As dificuldades em separar a rotina de casa com a do trabalho, problemas técnicos com o sistema do órgão e a exigência para mais horas de trabalho também foram citadas negativamente. Todavia, De Masi (2014) ameniza a questão do isolamento social, frisando que a redução do relacionamento com colegas de 
trabalho é suprimida por meio do maior número de relacionamentos familiares, com vizinhos e outros amigos.

E o teletrabalhador precisa ainda se adaptar as exigências ergonômicas do órgão, que deve estabelecer parâmetros de como deverá ser o ambiente de trabalho em relação a ergonomia, luminosidade, ventilação, entre outros (BOHLER, 2019). Em sua pesquisa sobre teletrabalho no contexto da pandemia do novo Coronavírus, Bridi et al (2020) relata que $57,06 \%$ dos respondentes avaliaram as condições de trabalho, quanto a ergonomia e aos equipamentos e tecnologias disponíveis para a realização das atividades do teletrabalho como sendo razoáveis, porém 12,14\% declararam que suas condições de trabalho em relação a ergonomia são péssimas. Todavia, a IN 65 coloca como sendo responsabilidade do servidor providenciar as condições físicas e tecnológicas necessários a realização do seu trabalho no home office.

Outra reclamação de alguns funcionários quanto as condições de trabalho tem sido o aumento da carga horária de trabalho diária e da quantidade de dias trabalhados semanalmente no home office. Os resultados da pesquisa de Brid et al (2020) por exemplo, revelaram que houve um aumento de $113,69 \%$ de trabalhadores que executam suas atividades laborais por mais de 8 horas diárias no trabalho remoto no momento da pandemia do CovidI9, sobrecarregando os servidores no sentido de mais trabalho, em termos de horas e dias trabalhados, gerando um ritmo mais acelerado.

E também com a implatação do teletrabalho surgem diversos desafios para a gestão de pessoas, no que diz respeito à supervisão praticada via teletrabalho. Os padrões de supervisão, de descentralização e autonomia, além da credibilidade no teletrabalhador, traçam uma discussão acerca do atual cenário brasileiro. Por isso, inicia-se uma nova procura a um perfil de gestor capaz de liderar pessoas virtualmente, por meio de modernas formas de gerenciá-las, motivá-las, bem como avaliá-las (SILVA, 2015).

Desse modo, a gestão focada nos resultados se intensifica, o que faz com que as metas e processos sejam mais objetivos. Além disso, também se identifica a necessidade de se gerar a isonomia em meio aos colaboradores, evitando assim conflitos entre os trabalhadores presenciais e os teletrabalhadores. Sendo assim, o obstáculo é conseguir implantar esse modelo de forma segura e gradual, conforme a realidade de cada organização (OLIVEIRA; PANTOJA, 2018).

A segurança da informação também é um desafio, dado que no teletrabalho informações variadas passam a não estar somente no âmbito do órgão, devendo-se por isso buscar ferramentas que garantam a segurança da informação nesse regime de trabalho (JÚNIOR, 2013). A MIT Technology review (2020) coloca como solução o poder da nuvem para oferecer suporte para o home office de forma produtiva e segura, porém alerta que quanto mais digitalização, mais segurança será demandada (de informação, de infraestrutura e de suporte técnico). Ou seja, são necessários mais investimentos na área de TI a fim de garantir o sucesso do teletrabalho na instituição.

Segundo Oliveira e Pantoja (2018) as desvantagens nesse tipo de trabalho podem ser reduzidas tanto para gestores quanto trabalhadores. Para isso, os processos de comunicação no regime de trabalho laboral devem ser elaborados como tática de desenvolvimento de pessoas e da organização, sendo incorporados gradualmente na estrutura tecnológica e na cultura organizacional da instituição. Outros estudos reforçam a cautela e os cuidados com o teletrabalho, no sentido de evitar que mínimos detalhes interfiram no bom andamento das tarefas.

\subsection{Vantagens e perspectivas do trabalho remoto}


São inúmeras as vantagens do teletrabalho. Para o servidor, a melhoria da qualidade de vida em geral, a possibilidade de administrar melhor seu tempo em equilíbrio com as demandas familiares, a facilitação para portadores de necessidades especiais, otimização de seu tempo ao evitar longas horas de deslocamento, a redução de custos com transporte, dentre outros aspectos. Já para a organização, um aumento de produtividade ao proporcionar um foco maior do servidor nas suas atividades principais, de forma concentrada e com menos interferências, bem como a diminuição de gastos com aluguel, infraestrutura e energia (MENDES; OLIVEIRA; VEIGA, 2020).

O teletrabalho também reflete na autonomia do colaborador em organizar seu modo de trabalhar, em especial, no que se refere ao espaço e ao tempo dedicado à atividade. Também, considera a diversidade dos indivíduos e seus variados aspectos, tem-se como exemplo a indicação do teletrabalho para mães que possuem filhos pequenos ou lactantes, para pessoas em idade mais avançada ou para jovens estudantes (ROCHA; AMADOR, 2018). Desse modo, a flexibilidade é a principal vantagem do trabalho remoto para o trabalhador. A MIT Technology review (2020) pontua que dentre as principais justificativas para a valorização da flexibilidade estão a preocupação com a qualidade de vida, possibilidade de ter mais tempo livre ou com a família, e alinhamento com horários mais produtivos.

Também são percebidos alguns benefícios para a sociedade, uma vez que há suspensão do deslocamento do funcionário para o trabalho, o que reduz os gastos com transportes públicos ou o número de automóveis nas rodovias, minimizando diversos problemas dos grandes centros urbanos na atualidade, como congestionamentos e a emissões de poluentes ambientais (OLIVEIRA; PANTOJA, 2018).

Portanto, com a contínua expansão do teletrabalho nas mais diversas áreas de atuação, já é possível estimar os benefícios que essa atividade pode gerar em médio e longo prazo para a sociedade e o governo. De acordo com pesquisas internacionais, a produtividade de um teletrabalhador é de 20 a $30 \%$ maior que a de seu colega presencial, em média (MELLO, 2014). Aliado a isso, têm-se questões como redução de deslocamentos, de gastos com transporte e da poluição resultante dentre outros fatores que justificam sua adoção. Além disso, os teletrabalhadores também relatam como uma grande vantagem a possibilidade de usufruir mais do contato com a família (BRIDI et al, 2020).

Em síntese, o teletrabalho já é realidade em muitas instituições públicas, pelo fato de admitir flexibilidade na execução de tarefas e metas dentro das definições de eficiência no meio organizacional e ainda proporciona benefícios práticos ao servidor público quanto ao aumento da sua qualidade de vida e otimização dos custos administrativos para a instituição (MENDES; OLIVEIRA; VEIGA, 2020).

Com efeito, essa mudança alterará a vida pública e em sociedade, em termos de tecnologia aplicada à produção, pois, trará diversas novas práticas no sistema de trabalho, além do que este novo modelo de ir ao trabalho se tornará uma nova tarefa não desgastante, porém, desafiadora, com maior produtividade nos locais de teletrabalho e com redução de custo operacionais, o que ratifica a sua vinculação ao melhor desempenho.

E provavelmente com a adoção quase massiva dessa modalidade devido a pandemia Novo Coronavírus, a tendência é que esse tipo de trabalho se torne cada vez mais comum mesmo após o fim da pandemia como aponta pesquisa da SOBRATT (202I) revelando que com o trabalho remoto cada vez mais consolidado como modelo de trabalho eficiente, chegou a $91 \%$ o percentual de profissionais qualificados que acreditam que o futuro do trabalho será de modelo híbrido, ou seja, revezando entre dias presenciais e remotos. A 
MIT Technology review (2020) defende que o modelo híbrido ideal seria I ou 2 dias em casa e o restante da semana no escritório.

Dessarte, a MIT Technology Review (2020) pontua que seja definitivamente ou em alguns períodos específicos, o fato é que o trabalho remoto será uma realidade para o mundo todo muito mais do que antes da pandemia.

\section{Considerações finais}

A administração pública vem buscando formas de aumentar a eficiência em suas diversas atividades e, nesse contexto, o teletrabalho tem sido adotado na busca de redução de custos, otimização do tempo e aumento da produtividade. Com experiências bastante positivas no âmbito da esfera pública brasileira, tem se mostrado uma excelente ferramenta para o enfrentamento de graves problemas nos grandes centros urbanos, revelando-se uma solução inteligente e sustentável para a atual realidade das cidades brasileiras.

Entretanto, essa pesquisa mostrou que, apesar dos notáveis avanços, ainda existem desafios a superar para que essa forma de trabalho possa alcançar plenamente seu potencial. Verificou que existem muitos desafios tanto para o telatrabalhador quanto para a organização, principalmente quanto a necessidade de maior produtividade, isolamento e questão de supervisão e controle do trabalho. Porém, foi visto que os ganhos são muito superiores tanto para o servidor, quanto para o órgão e sociedade. Mostrando-se, portanto, como uma alternativa de trabalho muito viável frente aos desafios que a modernização impõe e com reflexos positivos para toda sociedade.

Diante do exposto, percebe-se que o teletrabalho, apesar de aprentar ainda alguns entraves para sua consolidação, é um caminho sem volta e veio para ficar. Dessarte, considerando as características do teletrabalho, seja nas vantagens identificadas, seja na necessidade de ressalvas de sua adoção, observam-se fatores que exigem imperiosamente práticas de boa gestão por parte das organizações que adotam programas de teletrabalho a fim de lograr êxito na adoção desta modalidade de trabalho.

\section{Referências}

BRASIL. Câmara dos Deputados. PL 2723/2015. Disponível em: https://www.camara.leg.br/proposicoesWeb/fichadetramitacao? idProposicao $=1672572$. Acesso em: 22 fev. 2021.

Instrução Normativa № 65, DE 30 de julho de 2020. Estabelece orientações, critérios e procedimentos gerais a serem observados pelos órgãos e entidades integrantes do Sistema de Pessoal Civil da Administração Federal - SIPEC relativos à implementação de Programa de Gestão. Brasília: Casa Civil, 2020.

.Lei n. 12.55I, de 15 de dezembro de 20Ir. Diário Oficial da União, Brasília, I6 dez. 201 . Seção I. Disponível em: <Disponível em: http://www.planalto.gov.br/ccivil_03/_atozoII2014/201I/lei/li255I.htm >. Acesso em: $20 \mathrm{fev}$. 2021.

Secretaria-Geral da Presidência da República. Instrução Normativa no I, de 3i de agosto de 2018. Disponível em: http://www.in.gov.br/materia//asset_publisher/KujrwoTZC2Mb/content/id/39382838/dor-2018-o9-o3-instrucaonormativa-n-I-de-3I-de-agosto-de-2018-39382704. Acesso em: 2I fev. 202I. 
BRIDI, Maria Aparecida et al. O trabalho remoto/home-office no contexto da pandemia COVID-I9. Curitiba: UFPR, GETS, REMIR, 2020.

BOHLER, Fernanda Ribas. O teletrabalho no setor público: um estudo junto aos teleservidores do TRT do Paraná. Defesa em 27 setembro, 2019. I45 f. Dissertação (Mestrado em Sociologia) - Setor de Ciências Humanas da Universidade Federal do Paraná, 2019.

DE MASI, Domenico. O futuro do trabalho: fadiga e ócio na sociedade pós-industrial. II $^{\underline{a}}$ ed. Tradução de Yadyr A. Figueiredo. Rio de Janeiro: José Olympio, 2014.

GOULART, Joselma Oliveira. Teletrabalho: alternativa de trabalho flexível. Brasília: SENAC, 229 p., 2009.

JÚNIOR, Jessé de Souza Oliveira. Teletrabalho: vantagens e desvantagens para indivíduos, organizações e sociedade, 2013. Disponível em: https://social.stoa.usp.br/articles/oo28/973I/Oliveira_Jr_-_Teletrabalho_-_TCC__MBA_USP_GE_TI-20II.pdf. Acesso em: I8 fev. 2021.

LEITE, Ana Luiza; MULLER, Isabela Regina Fornari. Teletrabalho no serviço público: estudo de caso no Ministério Público de Santa Catarina - MPSC. In: XX SEMEAD Seminários em Administração, nov 2017. Disponível em:

https://login.semead.com.br/2osemead/arquivos/I275.pdf. Acesso em: 20 fev. 20201.

MELLO, Álvaro. Brasil já conta com ao menos 12 milhões de teletrabalhadores, garante Álvaro Mello. Sociedade Brasileira de Teletrabalho e Teleatividades - SOBRATT. 2014. Disponível em: <http://www.sobratt.org.br/index.php/o8042014-brasil-ja-conta-com-aomenos-I2-milhoes-de-teletrabalhadores-garante-alvaro-mello/>. Acesso em: 22 fev. 202I.

MENDES, Ricardo Augusto de Oliveira. OLIVEIRA, Lucio Carlos Dias. VEIGA, Anne Gabriela Bastos. A viabilidade do teletrabalho na administração pública brasileira.

Brazilian Journal of Development, Curitiba, v. 6, n. 3, p. $12745^{-12759}$ mar. 2020. ISSN 2525$876 \mathrm{I}$.

MIT TECHNOLOGY REVIEW. Special Edition Home Office. Work anywhere. MIT Technology Review, FGV IBRE, FGV Saúde e FGV IDE, 2020. Disponível em: http://www.sobratt.org.br/sitezor5/wp-content/uploads/202I/oI/MIT-SPECIALEDITION-HOME-OFFICE.pdf. Acesso em i abr. 202I.

OLIVEIRA, Míriam Aparecida; PANTOJA, Maria Júaia. Perspectivas e desafios do teletrabalho no setor público. In: Congresso Internacional de Desempenho do Setor Público, 2., 2018, Florianópolis. Anais eletrônicos... Florianópolis. Disponível em: 〈htp://www.cidesp.com.br/inde.php/Icidesp/2cidesp/paper/view/88I. Acesso em: 20 fev. 202I. 
O'NEILL, Thomas et al. Predicting telework success: an exploration of personality, motivational, situational, and job characteristics. New Technology, Work and Employment, v. 24, n. 2, 2009.

REIS, Junior Alves do. O Teletrabalho e a Lei 13.467/2017. Goiatuba-GO, 2018. Disponível em: https://junin7.jusbrasil.com.br/artigos/612507652/o-teletrabalho-e-a-lei-I3467-2017. Acesso em: 22 fev. 2021.

ROCHA, Cháris Teles Martins da; AMADOR, Fernanda Spanier. O teletrabalho: conceituação e questões para análise. Cadernos Ebape.br, v.ı6, n. I, Rio de Janeiro, jan. /mar., 2018.

SILVA, Aimée Mastella Sampaio da. A Aplicação do Teletrabalho no Serviço Público Brasileiro. In: $3^{\circ}$ Congresso Internacional de Direito e Contemporaneidade: mídias e direitos da sociedade em rede. Anais. Santa Maria: UFSM, 2015.

Sociedade Brasileira de Teletrabalho e Televendas - SOBRATT. Aprovada resolução que regulamenta o teletrabalho no Poder Judiciário. 2016. Disponível em:

〈http://www.sobratt.org.br/index. php/14062016〉. Acesso em: I9 fev. 2021.

. Orientação para implantação e prática do teletrabalho e home office. Cartilha, nov. 2020. Disponível em: http://www.sobratt.org.br/sitezors/wpcontent/uploads/2020/12/Cartilha-Teletrabalho.pdf. Acesso em I abr. 2021.

. Teletrabalho: Jornada Híbrida se consolida como preferida dos trabalhadores, 202I. Disponível em: http://www.sobratt.org.br/index.php/I501202I-teletrabalho-jornadahibrida-se-consolida-como-preferida-dos-trabalhadores/. Acesso em: 27 fev. 2021. 